\title{
Study of the Energy Performance of Different PV Arrays Configurations Under Partial Shading
}

\author{
Mustapha Elyaqouti ${ }^{1}$, Driss Izbaim ${ }^{2}$ and Lahoussine Bouhouch ${ }^{1}$ \\ ${ }^{1}$ Laboratory of Materials and Reneweble Energies (LMER), Ibn Zohr University, Agadir, Morocco \\ ${ }^{2}$ Laboratory of Metrology and Treatment Information (LMTI), Ibn Zohr University, Agadir, Morocco \\ elyaqouti@gmail.com
}

Keywords: Photovoltaic Arrays, Partial shading, Simscape, Total Cross Tied, Bridge Linked, Honey-Comb.

Abstract: The objective of this paper is to study the energy performance and electrical behavior of possible configurations for photovoltaic Arrays under different partial shading scenarios in order to determine the most suitable and cost effective configuration. The studied configurations in this work are: Series (S), parallel (P), series-parallel (SP), Total Cross Tied (TCT), Bridge Linked (BL) and Honey-Comb (HC). The simulation results provide information on the electrical behavior and energy efficiency of PV Arrays under different scenarios of partial shading and in uniform conditions.

\section{INTRODUCTION}

Solar energy is one of the most abundant sources of renewable energy on earth with an annual amount of 5.46x1024 J (Ajiwiguna, 2016). It should be said that this source is a solution in prospect for the world energy crisis (Abdulkadir, 2013). One form of the latter is photovoltaic energy, which is the result of the transformation of light energy into electrical energy thanks to the absorption of light radiation by semiconductor materials (Petibon, 2009). This conversion is carried out by means of an elementary device called a photovoltaic cell. The voltage generated by a solar cell is limited to the gap value of the material from which it comes. It is therefore necessary to combine several cells to have photovoltaic modules in order to provide sufficient power for domestic applications.

In order to obtain high powers at a suitable voltage, the PV modules are combined to form a photovoltaic field. Practically, the partial shading is one of the problems reducing the energy production of these Arrays. It can be caused by clouds, trees, nearby buildings, chimneys, snow, dust, dirt and bird droppings (Belhachat, 2015).

Losses related to shading can be reduced either by using MPPT techniques to extract the global maximum power point, or by adding additional connections between adjacent modules (Belhachat, 2015). There are in the literature several configurations for the interconnect modules in order to reduce these losses (Diaz-Porado, 2014, Ramaprabha, 2012, Ishaque, 2011 \& Nguyen, 2015).

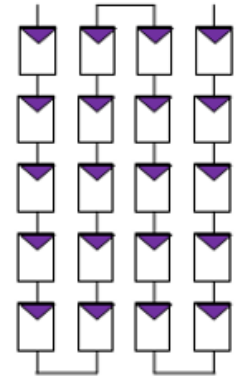

(a)

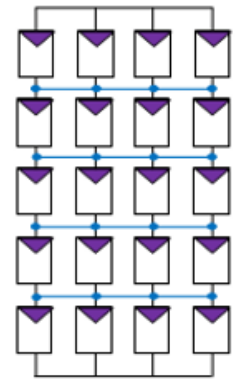

(d)

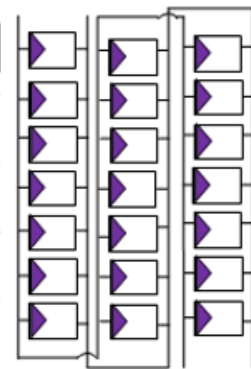

(b)

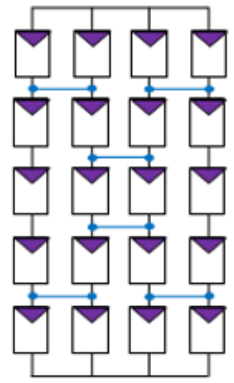

(e)
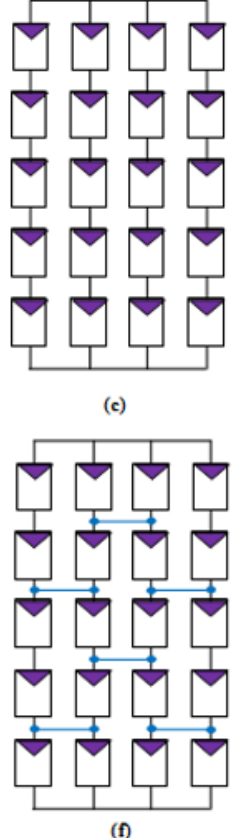

Figure 1: Wiring diagram: (a) Serial connection (S), (b) Parallel connection (P), (c) Serial-parallel connection (SP), (d) Total Cross Tied connection (TCT), (e) HoneyComb connection (HC) and (f) Bridge Linked connection (BL)

As shown in figure 1, these configurations are Series (a), parallel (b), series-parallel (c), Total Cross 
Tied (d), Bridge Linked (e) and Honey-Comb (f). The series connection of PV modules increases the voltage of the PV field while the parallel connection increases the current. Both of these connections are the basis of any mode of interconnection.

In this paper, we present the study of the energy performance of six possible configurations for photovoltaic Arrays under different partial shading scenarios. The purpose is to determine the optimal configuration.

Our paper is organized as follows: After an introduction, the modelling of the PV field under partial shading is described in the second section. The third section is devoted to the presentation and analysis of the simulations results and finally we conclude our work.

\section{MODELING THE PV ARRAY UNDER PARTIAL SHADING}

\subsection{Modelling of a PV module}

The electrical modelling and characterization of $\mathrm{PV}$ modules is an essential step to optimize the operation of photovoltaic systems. A reliable and accurate model will help predict the power output of a PV plant regardless of weather conditions (Hasan, 2016). Several models have been presented in the literature to model and characterize PV modules (Koohi-Kamali, 2016 \& Chin, 2015). These models are of two types: Either they model the efficiency of the photovoltaic generator (or a direct expression which determines the maximum power at the PVG output), or they model the current and the voltage of the module, and consequently the electric power (Stoyanov, 2011). This modelling is generally used to approximate the output of the PVG as a function of the two inputs which are the received solar illumination and the temperature of the module. This latter is the operating temperature of the photovoltaic cells (Jones, 2002).

The photovoltaic generator which is the subject of our characterization is of the BP Solar MSX-64 type. These electrical characteristics under standard test conditions (STC: $G=1000 \mathrm{~W}, T=25^{\circ} \mathrm{C}$ ) are provided in Table 1.

In order to model the electrical behavior of the PV module, we used the Simscape tool from Matlab/Simulink [16]. Figure 2 shows the PV module diagram under test in Simscape.
Table 1: Electrical characteristics of the MSX-64 PV module [15]

\begin{tabular}{|c|c|}
\hline Parameter & Value \\
\hline Maximum power $P_{\max , c}$ & $64 \mathrm{~W}$ \\
\hline $\begin{array}{l}\text { Voltage at maximum power point } \\
V_{m p p}\end{array}$ & $17.5 \mathrm{~V}$ \\
\hline $\begin{array}{l}\text { Current at maximum power point } \\
\text { Impp }\end{array}$ & $3.66 \mathrm{~A}$ \\
\hline Nominal short-circuit current $I_{s c, r e f}$ & $4 \mathrm{~A}$ \\
\hline Nominal open circuit voltage $V_{o c, r e f}$ & $21.3 \mathrm{~V}$ \\
\hline Temperature coefficient $\beta_{0}$ of $V_{o c}$. & $-(80 \pm 10) \mathrm{mV} /{ }^{\circ} \mathrm{C}$ \\
\hline Temperature coefficient $\alpha_{0}$ of $I_{s c}$ & $\begin{array}{c}(0.065 \pm 0.015) \\
\% /{ }^{\circ} \mathrm{C}\end{array}$ \\
\hline Power temperature coefficient of $\gamma_{0}$ & $-(0.5 \pm 0.05) \% /{ }^{\circ} \mathrm{C}$ \\
\hline NOCT & $47 \pm 2{ }^{\circ} \mathrm{C}$ \\
\hline
\end{tabular}

\subsection{Modelling of the PV field}

To study the effect of partial shading on the PV field production, we used the Simscape tool from Matlab/Simulink to simulate and analyze the six modes of interconnect PV modules ( $\mathrm{S}, \mathrm{P}, \mathrm{SP}, \mathrm{TCT}$, $\mathrm{HC}$ and $\mathrm{BL}$ ). The PV field under study consists of $6 \times 4$ $64 \mathrm{~W}$ modules (MSX-64). Figure 3 shows the diagram of the PV field with TCT configuration.

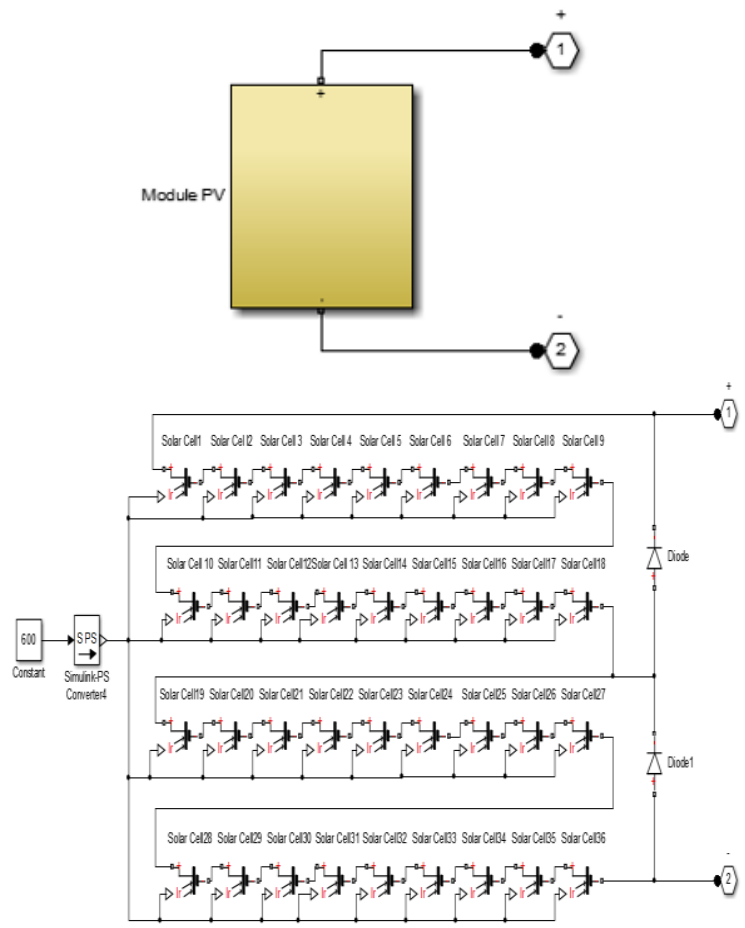

Figure 2: Diagram of the PV module in Simscape 


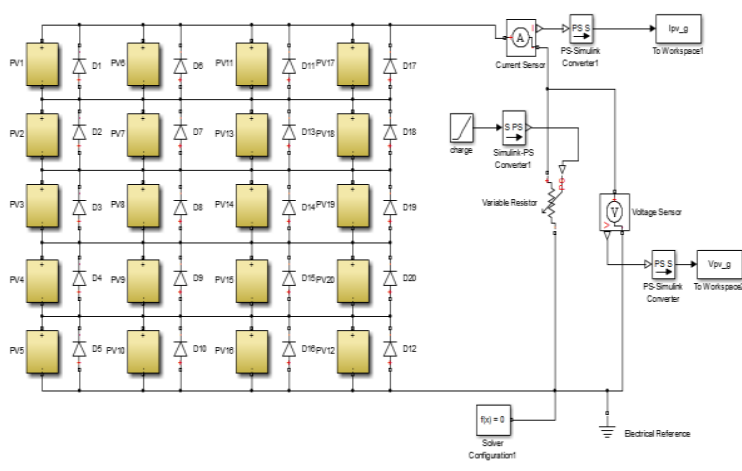

Figure 3: Diagram of the PV array in Simscape with the TCT connection

\section{SIMULATION RESULTS}

The objective of this section is to present the simulation results of the six possible configurations for PV Arrays under different partial shading scenarios to determine the optimal configuration. The partial shading scenarios tested in our case are as follows:

- S1: A row completely and uniformly shaded;

- S2: A row completely and unevenly shaded;

- S3: A column is completely and uniformly shaded;

- S4: A column completely and unevenly shaded;

- S5: A random distribution of shading.

The solar irradiance values used in the simulation for the five scenarios already mentioned are summarized in Table 2.

In order to show the influence of shading on the current-voltage and power-voltage output characteristics of the studied PV field, we have compared in figures 4 to 9 these characteristics under uniform conditions (without shading) and with shading (scenario S5).

So as to evaluate the PV field energy production with and without shading, we have presented in tables 3 and 4 the simulation results concerning the maximum power produced by the PV field under uniform conditions $\left(G=1000 \mathrm{~W} / \mathrm{m}^{2}\right.$ and $\left.T=25^{\circ} \mathrm{C}\right)$ and with shading for the six configurations ( $\mathrm{S}, \mathrm{P}, \mathrm{SP}$, TCT, BL and HC) as well as the percentage of relative power loss calculated by the following formula:

$$
\Delta P=\frac{P_{m p p, n o}-P_{m p p, o m}}{P_{m p p, n o}}
$$

With $P_{m p p, n o}$ and $P_{m p p, o m}$ are respectively the maximum power produced by the PV field under normal conditions (without shading) and under shading.
Table 2: Solar irradiance on the PV field for five scenarios

\begin{tabular}{|c|c|c|c|c|c|}
\hline Scenario & Column & String 1 & String $\mathbf{2}$ & String 3 & String 4 \\
\hline \multirow{4}{*}{ S1 } & 1 & 400 & 400 & 400 & 400 \\
\cline { 2 - 6 } & 2 & 1000 & 1000 & 1000 & 1000 \\
\cline { 2 - 6 } & 3 & 1000 & 1000 & 1000 & 1000 \\
\cline { 2 - 6 } & 4 & 1000 & 1000 & 1000 & 1000 \\
\cline { 2 - 6 } & 5 & 1000 & 1000 & 1000 & 1000 \\
\hline \multirow{4}{*}{ S2 } & 1 & 200 & 400 & 600 & 800 \\
\cline { 2 - 6 } & 2 & 1000 & 1000 & 1000 & 1000 \\
\cline { 2 - 6 } & 3 & 1000 & 1000 & 1000 & 1000 \\
\cline { 2 - 6 } & 4 & 1000 & 1000 & 1000 & 1000 \\
\hline \multirow{4}{*}{ S3 } & 5 & 1000 & 1000 & 1000 & 1000 \\
\cline { 2 - 6 } & 1 & 500 & 1000 & 1000 & 1000 \\
\cline { 2 - 6 } & 2 & 500 & 1000 & 1000 & 1000 \\
\cline { 2 - 6 } & 3 & 500 & 1000 & 1000 & 1000 \\
\cline { 2 - 6 } & 4 & 500 & 1000 & 1000 & 1000 \\
\hline \multirow{4}{*}{ S4 } & 5 & 500 & 1000 & 1000 & 1000 \\
\cline { 2 - 6 } & 2 & 200 & 1000 & 1000 & 1000 \\
\cline { 2 - 6 } & 3 & 500 & 1000 & 1000 & 1000 \\
\cline { 2 - 6 } & 4 & 700 & 1000 & 1000 & 1000 \\
\cline { 2 - 6 } & 5 & 900 & 1000 & 1000 & 1000 \\
\hline \multirow{5}{*}{ S5 } & 1 & 200 & 400 & 1000 & 1000 \\
\hline & 2 & 300 & 600 & 400 & 1000 \\
\hline & 3 & 1000 & 1000 & 400 & 1000 \\
\hline & 4 & 1000 & 1000 & 1000 & 900 \\
\hline & 5 & 1000 & 1000 & 800 & 800 \\
\hline
\end{tabular}

Table 3: Power produced by the PV array under uniform conditions STC for the six configurations

\begin{tabular}{|c|c|c|c|}
\hline Scenarios & $\boldsymbol{P}_{\boldsymbol{m p} \boldsymbol{p}, \boldsymbol{n o}}$ & $\boldsymbol{V}_{\boldsymbol{m p p} \boldsymbol{n} \boldsymbol{n o}}$ & $\boldsymbol{I}_{\boldsymbol{m p p} \boldsymbol{n} \boldsymbol{n o}}$ \\
\hline $\mathrm{P}$ & 1286.4 & 17.013 & 75.613 \\
\hline $\mathrm{S}$ & 1287.1 & 341.772 & 3.766 \\
\hline $\mathrm{SP}$ & 1287.6 & 86.044 & 14.964 \\
\hline $\mathrm{TCT}$ & 1287.6 & 86.044 & 14.964 \\
\hline $\mathrm{BL}$ & 1287.6 & 86.044 & 14.964 \\
\hline $\mathrm{HC}$ & 1287.0 & 86.044 & 14.965 \\
\hline
\end{tabular}

The analysis of the obtained results allows us to notice that the parallel configuration $(\mathrm{P})$ is almost the most efficient configuration for partial shade (except in case of scenario 3). However, the high value of the current generated by this configuration and its low voltage make it unsuitable for photovoltaic applications (Buddala, 2013, Ramaprabha, 2010 \& Gao, 2009). By analyzing the results of the five remaining configurations $(\mathrm{S}, \mathrm{P}, \mathrm{SP}, \mathrm{TCT}, \mathrm{BL}$ and $\mathrm{HC}$ ), we can conclude that:

- The six configurations S, P, SP, TCT, BL and HC give the same maximum power under uniform conditions (without shading);

- The S, SP, TCT, BL and HC configurations give the same maximum power when a row or a column is entirely (uniformly or not) shaded ( $\mathrm{S} 1$ and $\mathrm{S} 2$ ); 
- The SP, TCT, BL and HC configurations give the same maximum power when a column is entirely and uniformly shaded (S3);

- The TCT configuration is the one which gives the best performance when a column is entirely and

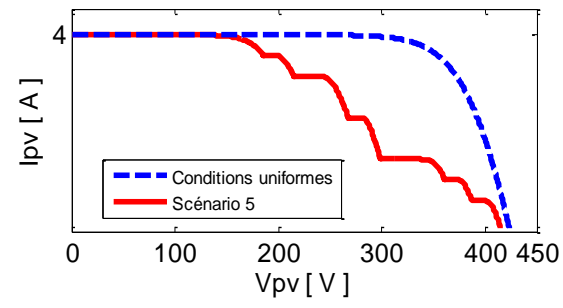

unevenly shaded as well as during a random distribution of shading (S4 and S5).

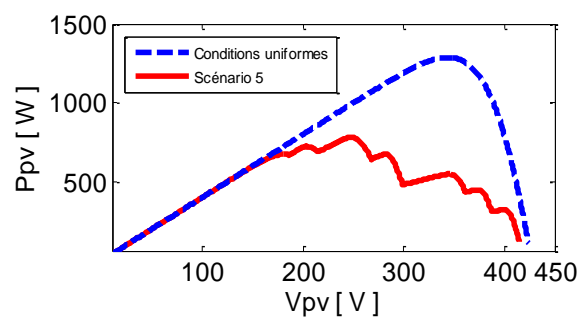

Figure 4: $I_{p v^{-}} V_{p v}$ and $P_{p v^{-}} V_{p v}$ characteristic of the PV field of the S configuration
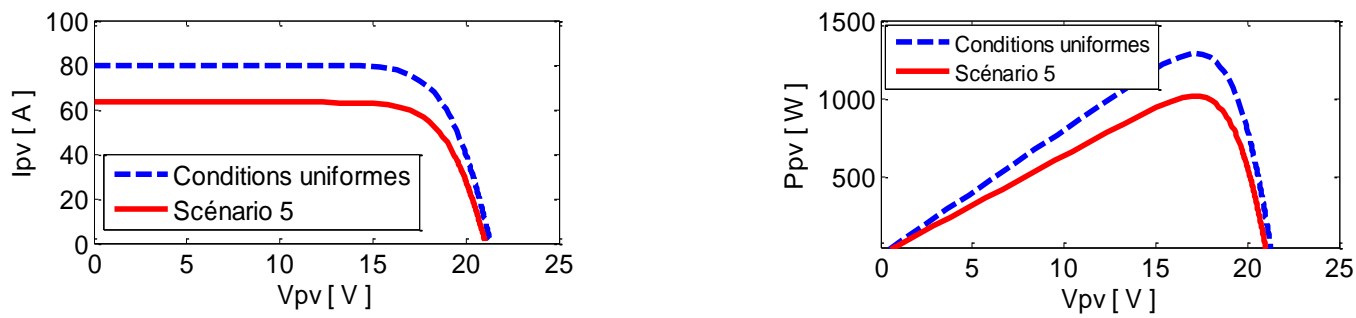

Figure 5: $I_{p v^{-}} V_{p v}$ and $P_{p v^{-}} V_{p v}$ characteristic of the PV field of the $\mathrm{P}$ configuration
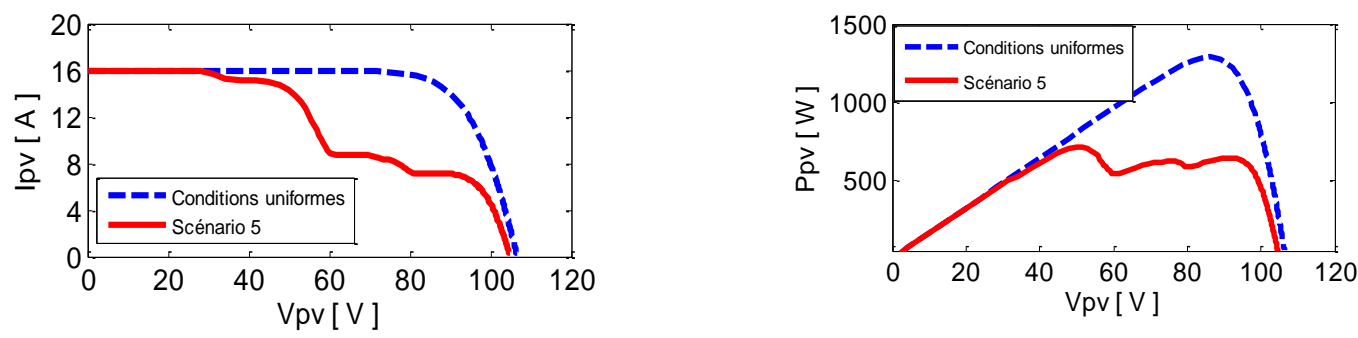

Figure 6: $I_{p v^{-}} V_{p v}$ and $P_{p v^{-}} V_{p v}$ characteristic of the PV field of the S-P configuration
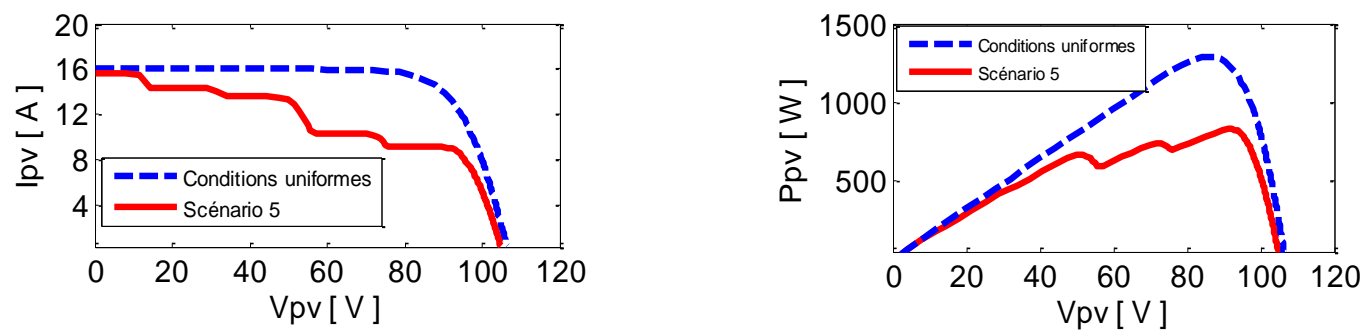

Figure 7: $I_{p v}-V_{p v}$ and $P_{p v}-V_{p v}$ characteristic of the PV field of the TCT configuration
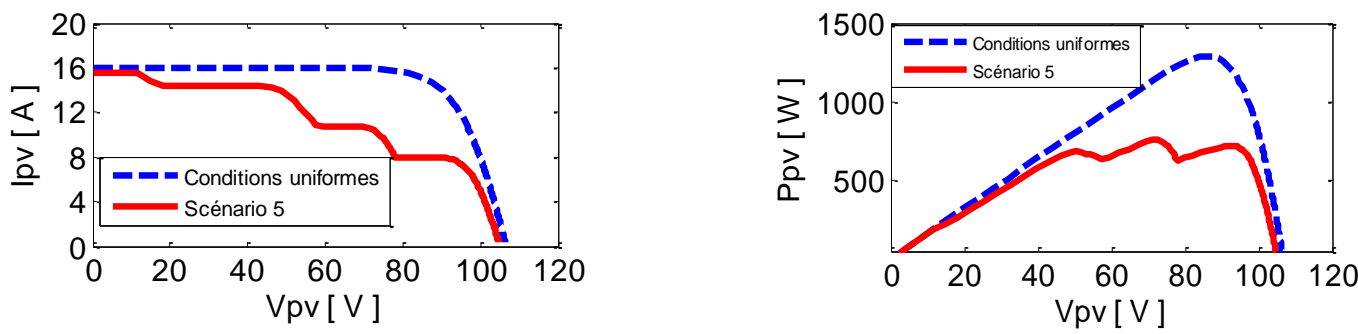

Figure 8: $I_{p v^{-}} V_{p v}$ and $P_{p v}-V_{p v}$ characteristic of the PV field of the BL configuration 

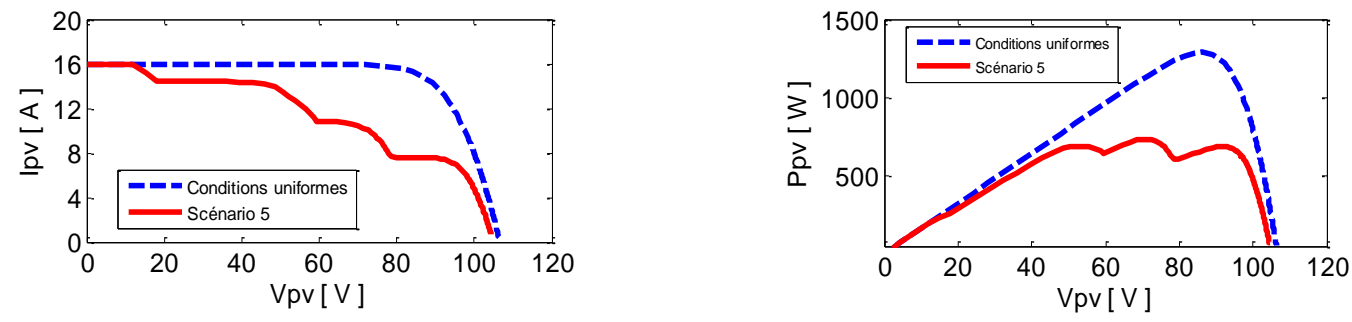

Figure 9: $I_{p v^{-}} V_{p v}$ and $P_{p v}-V_{p v}$ characteristic of the PV field of the HC configuration

Table 4: Simulation results of the different scenarios

\begin{tabular}{|c|c|c|c|c|c|}
\hline Scenario & Configurations & $\boldsymbol{P}_{m p p, o p}$ & $V_{m p p, o p}$ & $I_{m p p, o p}$ & $\triangle P(\%)$ \\
\hline \multirow{6}{*}{ S1 } & $\mathrm{P}$ & 1129.4 & 16.9708 & 66.55 & 12.20 \\
\hline & $\mathrm{S}$ & 1011.7 & 270.83 & 3.74 & 21.40 \\
\hline & $\mathrm{SP}$ & 1011.6 & 67.47 & 14.99 & 21.44 \\
\hline & TCT & 1011.6 & 67.47 & 14.99 & 21.44 \\
\hline & $\mathrm{BL}$ & 1011.6 & 67.47 & 14.99 & 21.44 \\
\hline & $\mathrm{HC}$ & 1011.6 & 67.47 & 14.99 & 21.40 \\
\hline \multirow{6}{*}{ S2 } & $\mathrm{P}$ & 1156.7 & 17.17 & 67.35 & 10.08 \\
\hline & $S$ & 1013.7 & 271.56 & 3.73 & 21.24 \\
\hline & SP & 1013.4 & 67.53 & 15.01 & 21.30 \\
\hline & TCT & 1013.1 & 67.52 & 15.00 & 21.32 \\
\hline & $\mathrm{BL}$ & 1013.4 & 67.53 & 15.01 & 21.30 \\
\hline & $\mathrm{HC}$ & 1013.4 & 67.53 & 15.00 & 21.26 \\
\hline \multirow{6}{*}{ S3 } & $\mathrm{P}$ & 1122.6 & 16.92 & 66.35 & 12.73 \\
\hline & $\mathrm{S}$ & 944.7 & 252.99 & 3.73 & 26.60 \\
\hline & SP & 1124.2 & 85.48 & 13.15 & 12.69 \\
\hline & TCT & 1124.2 & 85.48 & 13.15 & 12.69 \\
\hline & $\mathrm{BL}$ & 1124.2 & 85.48 & 13.15 & 12.69 \\
\hline & $\mathrm{HC}$ & 1124.2 & 85.48 & 13.15 & 12.65 \\
\hline \multirow{6}{*}{ S4 } & $\mathrm{P}$ & 1129.4 & 16.97 & 66.55 & 12.20 \\
\hline & $\mathrm{S}$ & 991.3 & 278.06 & 3.56 & 22.99 \\
\hline & SP & 1034.6 & 86.61 & 11.95 & 19.65 \\
\hline & TCT & 1093.8 & 87.50 & 12.50 & 15.05 \\
\hline & $\mathrm{BL}$ & 1074.2 & 88.25 & 12.17 & 16.57 \\
\hline & $\mathrm{HC}$ & 1064.3 & 87.84 & 12.12 & 17.30 \\
\hline \multirow{6}{*}{ S5 } & $\mathrm{P}$ & 1012.4 & 16.97 & 59.60 & 21.30 \\
\hline & $\mathrm{S}$ & 782.4 & 247.44 & 3.16 & 39.21 \\
\hline & SP & 714.0 & 49.99 & 14.28 & 44.55 \\
\hline & TCT & 829.5 & 91.08 & 9.11 & 35.58 \\
\hline & $\mathrm{BL}$ & 755.7 & 71.42 & 10.58 & 41.31 \\
\hline & $\mathrm{HC}$ & 728.3 & 71.40 & 10.20 & 43.41 \\
\hline
\end{tabular}

\section{CONCLUSION}

In this paper, we have presented the study of the energy performance of six possible configurations for photovoltaic Arrays under different partial shading scenarios, namely: Series (S), parallel (P), series- parallel (SP), Total Cross Tied (TCT), Bridge Linked (BL) and Honey-Comb (HC). The simulation results indicate that all six configurations give the same maximum power under conditions without shading. The choice of the optimal configuration of the PV array in the case of partial shading depends on the 
scenario of the latter. In the case when a row or a column is entirely (uniformly or not) shaded (S1 and $\mathrm{S} 2$ ), all the configurations give the same maximum power except the $\mathrm{P}$ configuration. The four configurations SP, TCT, BL and HC give the same maximum power when a column is entirely and uniformly shaded (S3). Finally, the TCT configuration is the one which gives the best performance when a column is entirely and unevenly shaded as well as during a random distribution of shading (S4 and S5).

\section{REFERENCES}

Ajiwiguna, T.A., Hamonangan, T., Kirom, M.R., 2016. 'Experimental study of thermal efficiency on plate-fin solar thermal collector'. ARPN Journal of Engineering and Applied Sciences, Vol. 11, No. 2, pp. 809-811.

Abdulkadir, M., Samosir, A.S., Yatim, A.H.M., Yusuf, S.T., 2013. 'A new approach of modeling, simulation of MPPT for photovoltaic system in Simulink model'. ARPN Journal of Engineering and Applied Sciences, Vol. 8, No. 7, pp. 488-494.

Petibon, S., 2009. 'Nouvelles architectures distribuées de gestion et de conversion de l'énergie pour les applications photovoltaiques'. PhD Thesis, University of Toulouse.

Belhachat, F., Larbes, C., 2015. 'Modeling, analysis and comparison of solar photovoltaic array configurations under partial shading conditions'. Solar Energy, Vol. 120, pp. 399-418.

Diaz-Porado, E., Cidras, J., Carrilo, C., 2014. 'Discrete I-V model for partially shaded PV-arrays'. Solar Energy, Vol. 103, pp. 96-107.

Ramaprabha, R., Mathur, B.L., 2012. 'A Comprehensive Review and analysis of solar photovoltaic Array Configurations under Partial Shaded Conditions'. International Journal of photoenergy, Vol. 2012, pp. 1-16.

Ishaque, K., Salam, Z., Taheri, H., Syaforuddin, 2011. 'Modeling and simulation of photovoltaic (PV) system during partial shading based on two-diode model'. Simulation Modelling Practice and Theory, Vol. 19, pp. 1613-1626.

Nguyen, X.H., 2015. 'Matlab/Simulink based modeling to study effect of partial shadow on solar photovoltaic array'. Environmental Systems Research, Vol. 4, pp. $1-10$

Hasan, M.A., Parida, S.K., 2016. 'An Overview of solar photovoltaic panel modeling based on analytical and experimental viewpoint'. Renewable and Sustainable Energy Reviews, Vol. 60, pp. 75-83.

Koohi-Kamali, S., Rahim, N.A., Mokhlis, H., Tyagi, V.V., 2016. 'Photovoltaic electricity generator dynamic modeling methods for smart grid applications'. Renewable and Sustainable Energy Reviews, Vol. 57, pp. 131-172.

Jena, D., Ramana, V.V., 2015. 'Modeling of photovoltaic system for uniform and non-uniform irradiance: A critical review'. Renewable and Sustainable Energy Reviews, Vol. 52, pp. 400-417.

Chin, V.J., Salam, Z., Ishaque, K., 2015. 'Cell modelling and model parameters estimation techniques for photovoltaic simulator application: A review'. Applied Energy, Vol. 154, pp. 500-519.

Stoyanov, L., 2011. 'Etude de différentes structures de systems hybrides à sources d'énergie renouvelables'. PhD Thesis, University of Corsica Pasquale Paoli, France.

Jones A.D., Underwood, C.P., 2002. 'A Modeling Method for Building-integrated Photovoltaic Power Supply'. Building Services Engineering Research and Technology, Vol. 23, No. 3, pp. 167-177.

https://www.smud.org/en/aboutsmud/environment/renewa ble-energy/documents/solar-regatta-photovoltaicspecs.pdf

http://www.mathworks.com/products/simscape/

Buddala, S.S., Vemuru, S., Devabhaktuni, V., 2013. 'Small signal modeling of diode in a parallel module subjected to partial shading'. EIT 2013, IEEE International Conference on Electro/Information Technology, pp. 1-5.

Ramaprabha, R., Mathur, B., Murthy, M., Madhumitha, S., 2010. 'New Configuration of Solar Photo Voltaic Array to Address Partial Shaded Conditions'. 3rd International Conference on Emerging Trends in Engineering and Technology (ICETET), pp. 328-333.

Gao, L., Dougal, R.A., Liu, S., Lotova, A.P., 2009. 'Parallel-Connected Solar PV system to address partial and rapidly fluctuating shadow conditions'. IEEE Transactions on Industrial Electronics, Vol. 56, Issue 5, pp. 1548-1556. 